\title{
Magnitude and Associated Factors of Delayed Immunization Among Children Aged 11 -23 Months in Edagahamus town, Tigray, Ethiopia, 2018.
}

Merhawit Gebremeskel Hagos

Aksum University

Teferi Gebru Gebremeskel ( $\nabla$ teferigebru12@gmail.com )

Aksum university https://orcid.org/0000-0002-8276-5685

Selam Shushay Kassahun

Adigrat University

Birhane Hailu Gebrezgi

Aksum University

Manay Kifle Woldegebriel

Aksum University

\section{Research article}

Keywords: Child immunization, Delay to be immunized, Vaccine-preventable diseases

Posted Date: October 15th, 2019

DOl: https://doi.org/10.21203/rs.2.11295/v2

License: (c) (1) This work is licensed under a Creative Commons Attribution 4.0 International License. Read Full License 


\section{Abstract}

Background: Delay in receiving immunization is a major public health problem that has been associated with vaccine-preventable disease epidemics. In Ethiopia, many children have not received the benefits of ageappropriate immunization; thus more than $90 \%$ of child deaths are largely due to preventable communicable diseases. Therefore, the aim of this study to assess the magnitude and factors associated with delayed immunization among 12 -23 months old children's in Edagahamus Town, Tigray, Ethiopia, and 2018 G.C. Methods: A community-based Cross-Sectional study was carried out on July1-30, 2018. A simple random sampling method was used to select study participants. Information was collected using a structured, pretested questionnaire. Vaccination dates were obtained from children's immunization cards and timeliness assessed based on the recommended age ranges. Data were entered and analyzed using SPSS version 20.0. Variable with P-value $<0.2$ in bivariate was exported to multivariate. The strength of association was identified using the odds ratio with a $95 \%$ confidence interval $(\mathrm{Cl})$ and the P-value of $<0.05$ in multivariate was taken statistically significant. Results: In this study, the overall magnitude of delayed immunization was $29.5 \%(95 \% \mathrm{Cl} 26.7-45)$. Private firm work of mothers (AOR=0.205 95\% $\mathrm{Cl} 0.068-0.617$ ) and Mothers who attend tertiary education (AOR $0.169,95 \% \mathrm{Cl} 0.032-0.882$ ) and secondary education (AOR $0.269,95 \% \mathrm{Cl}$ 0.114-0.636) had the protective effect of delayed immunization. But the sickness of the child (AOR=11.8, $95 \% \mathrm{Cl} 6.16-22.65)$ was a risk for delayed immunization. Conclusions: From the study, it is concluded that the magnitude of delayed immunization for children aged $12-23$ months is high (29.5\%) in Edagahamus. Delayed immunizations of children were predicted by the Mother's occupation, education, and the mother considered the child was too ill to undertake vaccination when it was due. Keywords: Child immunization, Delay to be immunized, Vaccine-preventable diseases

\section{Background}

Vaccine-preventable diseases cause over three million childhood deaths each year globally especially in developing countries $(1,2)$. Of the nearly 8.8 million less than five years old children die each year, greater than $20 \%$ of those deaths are due to Vaccine-preventable diseases (VPD)(3). VPD is a major cause of morbidity and mortality in children under five years of age in developing countries in general and Ethiopia in particular(4). Ethiopia has experienced many VPD outbreaks as well as morbidity and mortality from VPD(5, 6). According to EDHS 2016; childhood mortality rates have declined since 2000, however, infant and under-5 mortality rate in Ethiopia was 48/1000 and 67/1000 respectively(7). Immunization is the most important public health interference against VPD(8). It presently averts more than 2.5 million deaths every year in all age groups from diphtheria, tetanus, pertussis (whooping cough), and measles $(9,10)$.In Ethiopia nearly 4 in 10 children age 12-23 months have received all eight basic vaccinations; one dose each of BCG and measles and three doses each of Pentavalent, PCV, Rota and polio vaccine. Immunization is a key element of the health extension program package. However, timely and full vaccination coverage has not been completed in Ethiopia as planned, thus more than $90 \%$ of child deaths are largely due to preventable communicable diseases and nutritional disorders(20). In Edagahamus, the Expanded Program on Immunization (EPI) schedule is not applied as National advice for the timing of delivery of the schedule; as a result, many children have not received the benefits of timely and age-appropriate immunization. So, improving timely and age-appropriate immunization delivery would require a better understanding of reasons for the delay(18). 
Delays in receiving immunization have been reported globally(21). In the United States of America, up to 40 percent of parents delay or refuse their children's vaccine (16). $63.3 \%$ of the Gambian children had a delay in the mentioned age range to receive at least one of the studied vaccines(1). In Uganda, less than half of all children received all vaccines within the recommended time(22). According to different literatures, factors that are associated with delayed immunization includes; marital status, educational status, occupation, income, service accessibility, transportation, distance, place of birth, birth order, number of children in the household, sickness of the child, Forget/don't know the due date and so on $(1,19,22,23)$.

Today, parents' vaccine hesitancy may have been increased by celebrities' public airing of their concerns about vaccines (31-33). Parents commonly mention the fear of side effects as a reason for not vaccinating their children; eg, in Liberia, Somalia, Armenia. In some cases, an older sibling or acquaintance child has side effects parents refused vaccination for younger children. Little is known about delayed immunization and as per the investigators; no studies conducted to assess delayed immunization. Therefore, this study aimed to assess the magnitude and factors associated with delayed immunization among $12-23$ months old children in Edagahamus.

\section{Methods}

\section{Study setting}

A community-based cross-sectional study was conducted from July 1-30/ 2018 at Edagahamus city, Tigray regional state of Ethiopia. Edagahamus is founded in the eastern zone of Tigray, wereda Saesie Tsaida Amba; which is located $885 \mathrm{Km}$ north of the Ethiopian capital city of Addis Ababa, $105 \mathrm{Km}$ east of the Tigray capital city Mekelle and around $20 \mathrm{Km}$ near to Adigrat. Edagahamus is divided into four kebeles and the total population was 21,993 ; from those 10,031 were male and 11,962 were female (2006/2012 census). There is only one health center in Edagahamus and the total number of under two-year children is 795.

\section{Participants}

Sampled children aged $12-23$ months old living in Edagahamus and who fulfill the inclusion criteria were taken as the study population. Households that have one living child aged between 12-23 months old who have the vaccination card are included, While Households who have children aged between 12-23 months old who do not complete their vaccination (drop out) were excluded.

\section{Sample size determination and sampling technique}

The sample size was calculated using a single population proportion formula was used with the following assumption: Prevalence of children's who had delayed vaccination in Gambia $=63.3 \%$ (1),95\% of confidence interval(1.96), $5 \%$ margin of sampling error tolerated, $10 \%$ of non-response rate, then the final sample size are 393. A simple random sampling method was used to select study subjects using a sampling frame obtained from the health extension workers. The mothers' identity and the households' numbers that are used by the Health extension workers were used to identify the selected households. In the case of two or more mothers having a child's in the same household, one mother was selected using the lottery method. First, a list of all eligible participants was prepared in excel after obtained from the health extension workers. Then, the 
random number was generated using OpenEpi software and marked the selected one against the excel. Finally, each eligible study participant was contacted through the house to house visits. A second visit was done in case a mother was absent in the house during the first visit. If the mother is not available for the second time, a neighbor's mother with a child was contacted. Samples were allocated to each kebeles using a proportion to the size allocation.

\section{Study Variables}

\section{Dependent Variable}

Delayed immunization

\section{Independent Variables}

Socio-demographic and economic factors, Maternal/caregiver factors, Child's factors, and Service-related factors.

\section{Definition of terms}

BCG (birth - 8 weeks), Penta1, PCV1, Rota1 and OPV1 (6 weeks - 14 weeks); Penta2, PCV2, Rota2 and OPV2 (10 weeks - 18 weeks); Penta3, PCV3 and OPV3 (14 weeks - 24 weeks)] and measles vaccine (9 months 11 months). Timeliness of vaccination of a particular antigen was assessed against the WHO recommended range as already indicated above and Children who have delayed at receiving at least one vaccine considered as delayed (1). Timely: if the vaccine was received within the recommended period above. Delayed: if received after the window period. Penta-1 to Penta-3 dropout rate: the \% of children vaccinated for Penta- 1 who defaulted for Penta-3. BCG to Measles dropout rate: the \% of children vaccinated for BCG who defaulted for measles.

Health Extension Worker: In Ethiopia, against a backdrop of acute physician shortage, Health Extension Workers are assigned to local health posts and provide a package of essential interventions to meet population health needs at this level. Through the national Health Extension Program, HEWs are recruited among high school graduates in local communities, and undergo a one-year training program to deliver a package of preventive and basic curative services that fall under four main components: hygiene and environmental sanitation; family health services; disease prevention and control; and health education and communication (34).

\section{Data collection tools and techniques}

Data was collected by using an interviewer-administered and structured questionnaire adapted from WHO survey questions and related pieces of literature according to the objectives $(1,19,22,23,30)$. The questionnaire includes Socio-demographic and economic factors, Maternal/caregiver factors, Child's factors, and Service-related factors.

\section{Data quality assurance and control}


Five Midwife data collectors and supervisors were recruited from another area outside of the study site and they were given training for three days. The supervisors followed the process of data collection daily, checked the data completeness consistency and communicate with principal investigators daily.

\section{Data Processing and Analysis}

data was coded, cleaned, recorded and entered into Epi info 7and finally export to SPSS version 20.00 for analysis. Simple descriptive summary statistics were done. Tables, statements, charts, and graphs were used to present the result of the analyzed data. Associations between independent and dependent variables were analyzed first using bivariate logistic regression analysis. Variables that had $p<0.2$ on bivariate analysis were entered into multivariable logistic regression analysis. The statistical association between the different independent variables about dependent was measured using OR, AOR, 95\% Cl and P-values $<0.05$ was considered statistically significant.

\section{Results}

\section{Socio-demographic Character of the study participants}

A total of 393 mothers of children aged between 12-23 months old were interviewed from four kebeles, with a response rate of $100 \%$. Out of the total study subjects, $222(56.5 \%)$ have children aged $11-17$ months, while $171(43.5 \%)$ were aged $18-24$ months. The mean ( \pm SD) age of the children was $17( \pm 6)$ months old. Female children were 208 (52.9\%) of the total study subjects. The age range of mothers included in the study was 17-43 years, which is a childbearing age range. The mean $( \pm$ SD) age of the mothers was $29.4( \pm 5.3)$ years old. (Table 1)

\section{Maternity-related characteristics}

Overall 327(83.2\%) of mothers know the immunization schedule. A total of 278 (70.7\%) of the mothers got health education, particularly about immunization during antenatal and postnatal care while they were pregnant and after the birth of the child. (Table 2)

\section{Service-related characteristics}

Overall 44(11.2\%) returned home due to a lack of vaccine. About 246(62.6\%) mothers get advice during the immunization period mothers getting advice on adverse events following vaccination (Table 3 ).

\section{The magnitude of age untimely vaccination}

From the total respondents 116 (29.5\%, 95\% Cl26.7\%-45\%). had experienced delay at least one of their immunization. For BCG 41 (10.4\%) of the respondents were presented after the age of 8 weeks and delayed for up to two months. For the first dose of Pentavalent, PCV, Rota, and polio vaccines 7 (1.7\%) of the respondents were presented after the age of 14 weeks and delayed for up to one month and a half. For the second dose of Pentavalent, PCV, Rota, and polio vaccines 13(3.3\%) of the respondents were presented after the age of 18 weeks and delayed for up to two months. For the third dose of Pentavalent, PCV and polio vaccines $26(6.6 \%)$ of the respondents were presented after the age of 24 weeks and delayed for up to two 
months. For the measles vaccine, 29(7.3\%) of the children were presented after the age of 11 months and $5.2 \%$ and $1.4 \%$ were delayed for up to three and seven months respectively(figure 1 ).

\section{Factors associated with delayed immunization}

In the bivariate logistic regression maternal occupation, marital status, educational status, lack of vaccines, lack of appointment, sickness of the child's and "don't know" the due were associated with delayed immunization at $p$ - the value of $<0.2$. In multivariate logistic regression analysis sickness of the child, mothers' occupation and education have significantly associated. At should be in Children's of mothers who were employed at private occupations were less likely to delay their vaccines (AOR $0.20595 \% \mathrm{Cl} 0.068$ 0.617) compared to children's of mothers who were a housewife. Mothers who had tertiary education (AOR $0.169,95 \% \mathrm{Cl} 0.032-0.882$ ) and secondary education (AOR 0.269, 95\% Cl 0.114-0.636) were less likely to delay their infant's immunization compared to those mothers with no education. A sick child's on the appointment day were more likely to delay (AOR 11.36, 95\% $\mathrm{Cl} 4.68-27.55)$ than those healthy.

\section{Discussion}

This study aimed to assess the magnitude and factors associated with immunization delay among 12-23 months old children. In this study, the overall prevalence of delayed immunization among the study participants was found to be $29.5 \%$ (95\% Cl 26.7\%-45\%). other country experiences have shown the overall prevalence of delayed immunization can vary from the study done in Gambia $63.3 \%$ (1) to the study done in Atlanta $25.8 \%$ (24). This difference might be attributed due to the difference in educational background and degree of knowledge towards immunization and difference in the study population. However, it is similar to the study done among Norwegian children $44.7 \%$ (23). This is justified due to the similarity in the study population, Vaccinations are mainly provided by public health nurses and all services are voluntary and free of charge. The occupation was significantly associated with delayed vaccination; in this study private firm work of mothers was positively associated with timeliness, which is similar to the study done among Gambian children (1). The reasons may be multiple, for example, better knowledge about vaccination and time management and housewife women might be fully engaged at home with domestic tasks hence they tend to forget their children's vaccination appointments. The educational status of the mother/caretaker was a predictor for delayed child immunization; in this study maternal education beyond the secondary level was positively associated with timeliness, Similar to the study done in Nigeria(21), Gambia(1) and Iran(19). This is attributed because highly educated mothers are more willing to seeking care than other mothers. The sickness of the children was also associated with delayed vaccination similar to the study done in Nigeria and Shenzhen, China(21, 30). This may be around missed opportunities to vaccinate with mild illnesses. Socio-economic status and the number of children in the households were not predictors for delayed child's immunization in this study, which is different from studies in Gambia and Uganda, which indicates incomerelated factors hindered utilization of immunization services so that children's with several siblings were more likely to have untimely vaccinations, that higher cost and demands can easily discourage to vaccinate their children's $(1,22)$. This difference could be explained by the fact that free service for immunization is implementing in Ethiopia so that higher costs and demands were not a problem among families participated in this study. 


\section{Conclusions}

From the study, it is concluded that the magnitude of Delayed immunization for children aged 12-23 months is high (29.5\%) in Edagahamus. Delayed immunizations of children were predicted by the Mother's occupation, education had the protective effect of delay immunization and the mother considered the child was too ill to undertake vaccination when it was due was a risk for delayed immunization. Therefore it is important to consider education as vital for the attainment of full immunization which intern raises the need of the community and creates maternal awareness about the importance of child immunization. There is a need to disseminate information on the importance of mothers' occupation that most of the mothers with domestic works have more likely to delay immunization.

\section{Abbreviations}

BCG - Bacillus Calmette-Guerin , EDHS - Ethiopia Demographic Health Survey, EPI - Expanded Program on Immunization, FMOH - Federal Ministry of Health ,MDG - Millennium development goal ,MMR - MeaslesMumps-Rubella, $\mathrm{MoH}$ - Ministry of Health, MU, CHS - Mekele University College of Health Science, OPV Oral Polio Vaccine, SE - Side Effect, VPD - Vaccine-Preventable Diseases , PCV - Pneumonia Vaccine, SNNP

- Southern Nation and Nationalities, SOS - Sustainable Outreach Services, UNICEF - United Nations International Children's Education Fund, WHO - World Health Organization

\section{Declarations}

\section{Ethical consideration}

Ethical clearance was obtained from the Institutional Review Committee (IRC), College of Medicine and Health Sciences, Mekele University. Permission letter was received from those administrative bodies of the East Tigray Health Department, Edagahamus City, and selected kebeles written consent was obtained from all participants after they informed on the purpose of the study. Information's obtained from individuals participants was kept secure and confidential. Names and other identifying data of respondents were made by using code throughout the study process to obtain confidentiality. Finally, data were collected according to the standard questionnaire prepared.

\section{Consent for publication}

Not applicable

\section{Availability of data and materials}

The datasets used during the current study available from the corresponding author on reasonable request (Additional file 1).

\section{Computing interest}

The authors declare that they have no competing interests. 


\section{Funding}

Mekele University was our fund agent to conduct this study. The role of Mekele University was providing appropriate training to develop the proposal, funding money to our data collectors and following how the study is going on, finally, our University provides us basic training which was helpful for our study.

\section{Authors' contributions}

MG designed the study, performed statistical analysis, and drafted the paper. TG, SS, BH, and MK participated in paper writing. All authors contribute to the data analysis and read and approved the final paper.

\section{Acknowledgments}

We are highly indebted to all participants of the study, supervisors of data collection and data collectors for their worthy efforts and participation in this study. We are also thankful for administrative bodies at all levels who endorsed us to undertake these studies.a

\section{References}

1. Odutola A, Afolabi MO, Ogundare EO, Lowe-Jallow YN, Worwui A, Okabe J, et al. Risk factors for delay in age-appropriate vaccinations among Gambian children. BMC health services research. 2015;15(1):346.

2. Dayan GH, Shaw KM, Baughman AL, Orellana LC, Forlenza R, Ellis A, et al. Assessment of delay in ageappropriate vaccination using survival analysis. American journal of epidemiology. 2006;163(6):561-70.

3. Drain PK. Vaccine-Preventable Diseases and Immunization Programs. Global Health Education Consortium (GHEC): World Health Organization (WHO). 2012;2004.

4. Atnafu $\mathrm{A}$, Otto $\mathrm{K}$, Herbst $\mathrm{CH}$. The role of mHealth intervention on maternal and child health service delivery: findings from a randomized controlled field trial in rural Ethiopia. mHealth. 2017;3(9).

5. Hailey Gebretnsae Aregawi. Determinants of defaulting from completion of child immunization in Laelay Adiabo District, Tigray Region, Northern Ethiopia: A case-control study. 2017.

6. Etana B, Deressa W. Factors associated with complete immunization coverage in children aged 12-23 months in Ambo Woreda, Central Ethiopia. BMC public health. 2012;12(1):566.

7. ETHIOPIA DEMOGRAPHIC HEALTH SURVEY. 2016.

8. Mohammed RT. Assessment of factors associated with incomplete immunization among children aged 12-23 months in Ethiopia. 2016.

9. Organization WH. Global immunization data. February 2014. 2014.

10. Legesse E, Dechasa W. An assessment of child immunization coverage and its determinants in Sinana District, Southeast Ethiopia. BMC Pediatrics. 2015;15(1):31.

11. Federal Ministry of Health AA. COMPREHENSIVE MULTI-YEAR PLAN 2016 - 2020. 2015.

12. Negussie A, Kassahun W, Assegid S, Hagan AK. Factors associated with incomplete childhood immunization in Arbegona district, southern Ethiopia: a case-control study. BMC public health. 
2015;16(1):27.

13. Lakew Y, Bekele A, Biadgilign S. Factors influencing full immunization coverage among 12-23 months of age children in Ethiopia: evidence from the national demographic and health survey in 2011. BMC public health. 2015;15(1):728.

14. AWINO OJ. DETERMINANTS OF IMMUNIZATION COVERAGE AMONG CHILDREN AGED 12-23 MONTHS IN KENYA. 2016.

15. Salmon DA, Moulton LH, Omer SB, Patricia DeHart M, Stokley S, Halsey NA. Factors associated with refusal of childhood vaccines among parents of school-aged children: a case-control study. Archives of pediatrics \& adolescent medicine. 2005;159(5):470-6.

16. Haelle T. Delaying vaccines increases risks-With no added benefits. Scientific American. 2014.

17. Lisa M. Calhoun AME. Determinants and Coverage of Vaccination in Children in Western Kenya from a 2003 Cross-Sectional Survey. 2003.

18. Lieu TA, Black SB, Ray P, Chellino M, Shinefield HR, Adler NE. Risk factors for delayed immunization among children in an HMO. American Journal of Public Health. 1994;84(10):1621-5.

19. Mohammadbeigi A, Mokhtari M, Zahraei SM, Eshrati B, Rejali M. Survival analysis for predictive factors of delay vaccination in Iranian children. International journal of preventive medicine. 2015;6.

20. Health FDRoEMo. Health Sector Development Programme IV. 2010.

21. Sadoh AE, Sadoh WE, Uduebor J, Ekpe P, Iguodala O. Factors contributing to delay in commencement of immunization in Nigerian infants. Tanzania journal of health research. 2013;15(3).

22. Babirye JN, Engebretsen IM, Makumbi F, Fadnes LT, Wamani H, Tylleskar T, et al. Timeliness of childhood vaccinations in Kampala Uganda: a community-based cross-sectional study. PloS one. 2012;7(4):e35432.

23. Riise ØR, Nøkleby H, Laake I, Haugen IL, Storsæter J, Bergsaker MAR. Monitoring of timely and delayed vaccinations: a nation-wide registry-based study of Norwegian children aged< 2 years. BMC Pediatrics. 2015;15(1):180.

24. Smith PJ, Humiston SG, Marcuse EK, Zhao Z, Dorell CG, Howes C, et al. Parental delay or refusal of vaccine doses, childhood vaccination coverage at 24 months of age, and the Health Belief Model. Public health reports. 2011;126(2_suppl):135-46.

25. Smith PJ, Humiston SG, Parnell T, Vannice KS, Salmon DA. The association between the intentional delay of vaccine administration and timely childhood vaccination coverage. Public health reports. 2010;125(4):534-41.

26. Gilkey MB, McRee A-L, Magnus BE, Reiter PL, Dempsey AF, Brewer NT. Vaccination confidence and parental refusal/delay of early childhood vaccines. PloS one. 2016;11(7):e0159087.

27. Bobo JK, Gale JL, Thapa PB, Wassilak SG. Risk factors for delayed immunization in a random sample of 1163 children from Oregon and Washington. Pediatrics. 1993;91(2):308-14.

28. Hu Y, Li Q, Luo S, Lou L, Qi X, Xie S. Timeliness vaccination of measles-containing vaccine and barriers to vaccination among migrant children in East China. PloS one. 2013;8(8):e73264. 
29. Ujwala U. Ukey a DPD, Dr. Dhruv S. Chitrec, Dr. Srinivas Pusulurid. Factors Related To Delayed Immunisation Among Children Below 5 Years. International Journal of Biological \& Medical Research. 2011;2 (4):1171 - 2.

30. Lin $\mathrm{W}$, Xiong $\mathrm{Y}$, Tang $\mathrm{H}$, Chen $\mathrm{B}, \mathrm{Ni}$ J. Factors associated with delayed measles vaccination among children in Shenzhen, China: A case-control study. Human vaccines \& immunotherapeutics. 2014;10(12):3601-6.

31. Kennedy RF. Deadly immunity. Rolling Stone 2005 Jun 30-Jul 14. Also available from: URL: http://www.webcitation.org/5glaWmdym [cited 2011 Mar 28].

32. McCarthy J. Mother warriors: a nation of parents healing autism against all odds. New York: Dutton Adult; 2008.

33. Carrey J. The judgment for vaccines is in??? The Huffington Post. 2009 Apr 22 [cited 2009 Nov 9]. Available from: URL: http://www.huffingtonpost.com/jim-carrey/the-judgmentonvaccines_b_189777.html

34. World Health Organization, Global Health Workforce Alliance. Ethiopia's Human Resources for Health Programme. Accessed 8 November 2011.

\section{Tables}

Table 1: Sociodemographic characteristics of the respondents in Edagahamus, Tigray, Ethiopia, $2018(\mathrm{n}=393)$. 


\begin{tabular}{|c|c|c|c|}
\hline Variable & Category & Frequency & Percent (\%) \\
\hline \multirow[t]{2}{*}{ Sex of child } & Female & 208 & 52.9 \\
\hline & Male & 185 & 47.1 \\
\hline \multirow[t]{2}{*}{ Age of child } & 11-17 months & 222 & 56.5 \\
\hline & 18-24 months & 171 & 43.5 \\
\hline \multirow[t]{2}{*}{ Age of mother } & $\leq 30$ yrs. & 244 & 62.1 \\
\hline & $\geq 31$ yrs. & 149 & 37.9 \\
\hline \multirow[t]{2}{*}{ Religion } & Christian & 328 & 83.5 \\
\hline & Other & 65 & 16.5 \\
\hline \multirow[t]{3}{*}{ Marital status } & Married/active & 302 & 76.8 \\
\hline & never married & 39 & 9.9 \\
\hline & Separated/widowed and divorced & 52 & 13.2 \\
\hline \multirow[t]{2}{*}{ Ethnicity } & Tigray & 372 & 94.7 \\
\hline & Other & 21 & 5.4 \\
\hline \multirow[t]{4}{*}{ Educational level } & no education & 57 & 14.5 \\
\hline & Primary & 106 & 27.0 \\
\hline & Secondary & 191 & 48.6 \\
\hline & University/college & 39 & 9.9 \\
\hline \multirow[t]{5}{*}{ Occupation } & Governmental & 22 & 5.6 \\
\hline & Private & 59 & 15.0 \\
\hline & Daily & 40 & 10.2 \\
\hline & Student & 16 & 4.1 \\
\hline & Housewife & 256 & 65.1 \\
\hline \multirow[t]{4}{*}{ Average monthly income } & $<500$ birr & 42 & 10.7 \\
\hline & $500-1000$ & 119 & 30.3 \\
\hline & $>1000$ & 192 & 48.3 \\
\hline & Unknown & 42 & 10.7 \\
\hline \multirow[t]{3}{*}{ Birth order of the child } & $1^{\text {st }}$ born & 55 & 14.0 \\
\hline & $2^{\text {nd }}$ born & 161 & 41.0 \\
\hline & $>3^{\text {rd }}$ born & 177 & 45.0 \\
\hline
\end{tabular}

2: Distribution of maternity-related characteristics of Edagahamus, Tigray, Ethiopia, 2018 13) 


\begin{tabular}{|c|c|c|c|}
\hline Variable & Category & Frequency & $\begin{array}{l}\text { Percent } \\
(\%)\end{array}$ \\
\hline \multirow{2}{*}{$\begin{array}{l}\text { Health education about vaccination and related topics during } \\
\text { PNC/ANC }\end{array}$} & Yes & 278 & 70.7 \\
\hline & No & 115 & 29.3 \\
\hline \multirow[t]{2}{*}{ Place of birth } & Own home & 47 & 12.0 \\
\hline & $\begin{array}{l}\text { Health } \\
\text { facility }\end{array}$ & 346 & 88.0 \\
\hline \multirow[t]{2}{*}{ Illness of child on the appointment period } & Yes & 42 & 10.7 \\
\hline & No & 351 & 89.3 \\
\hline \multirow[t]{2}{*}{ Don't know it was due/forget } & Yes & 28 & 7.1 \\
\hline & No & 365 & 92.9 \\
\hline \multirow[t]{2}{*}{ Fear of side effect } & Yes & 27 & 6.9 \\
\hline & No & 366 & 93.1 \\
\hline \multirow[t]{2}{*}{ Do you think it is important to get a vaccine? } & Yes & 381 & 96.9 \\
\hline & No & 12 & 3.1 \\
\hline \multirow[t]{2}{*}{ Do you know immunization commences at birth? } & Yes & 311 & 79.1 \\
\hline & No & 82 & 20.9 \\
\hline \multirow[t]{2}{*}{ Do you know the immunization schedule? } & Yes & 327 & 83.2 \\
\hline & No & 66 & 16.8 \\
\hline \multirow[t]{2}{*}{ Do you think immunity could be achieved with vaccination? } & Yes & 362 & 92.1 \\
\hline & No & 31 & 7.9 \\
\hline \multirow[t]{2}{*}{ Do you think VPD could be serious? } & Yes & 342 & 87.0 \\
\hline & No & 51 & 13.0 \\
\hline
\end{tabular}

\section{3: Distribution of service-related characteristics of Edagahamus, Tigray, Ethiopia, 2018}

13).

\begin{tabular}{|c|c|c|c|}
\hline Variable & Category & Frequency & $\begin{array}{l}\text { Percent } \\
(\%)\end{array}$ \\
\hline \multirow[t]{3}{*}{ The child might develop side effect from the shot } & $\begin{array}{l}\text { Great } \\
\text { deal }\end{array}$ & 314 & 79.9 \\
\hline & A little & 61 & 15.5 \\
\hline & Not at all & 18 & 4.6 \\
\hline \multirow{2}{*}{$\begin{array}{l}\text { Advised you some vaccines had too serious SE during immunization } \\
\text { period }\end{array}$} & Yes & 246 & 62.6 \\
\hline & No & 147 & 37.4 \\
\hline \multirow[t]{2}{*}{ Satisfaction with the practice of providers } & Yes & 251 & 63.9 \\
\hline & No & 142 & 36.1 \\
\hline \multirow[t]{2}{*}{ Lack of vaccine } & Yes & 44 & 11.2 \\
\hline & No & 349 & 88.8 \\
\hline \multirow[t]{2}{*}{ Lack of appointment } & Yes & 20 & 5.1 \\
\hline & No & 373 & 94.9 \\
\hline
\end{tabular}


Table 4: Factors associated with delayed immunization among 11-23 months old children in Edagahamus Town, Tigray, Ethiopia, and 2018G.C

\begin{tabular}{|c|c|c|c|c|c|c|}
\hline iable & $\begin{array}{l}\text { Delay } \\
\mathrm{n}(\%)\end{array}$ & $\begin{array}{l}\text { Timely } \\
\text { n (\%) }\end{array}$ & COR & $P$ & AOR & $\mathrm{P}$ \\
\hline \multicolumn{7}{|l|}{ supation } \\
\hline jernmental & $2(9.1)$ & $20(90.9)$ & $0.184(0.042 ; 0.807)$ & 0.025 & $0.663(0.10-4.384)$ & 0.669 \\
\hline vate & 10(16.9) & $49(83.1)$ & $0.376(0.182 ; 0.779)$ & 0.008 & $0.205(0.068-0.617)$ & 0.005 \\
\hline Daily laborer & $28(70)$ & $12(30)$ & $4.304(2.088 ; 8.871)$ & 0.000 & $1.881(0.602-5.874)$ & 0.277 \\
\hline dent & $9(56.3)$ & $7(43.8)$ & $2.37(0.855 ; 6.58)$ & 0.097 & $3.462(0.707-16.95)$ & 0.125 \\
\hline Housewife & $90(35.2)$ & $166(64.8)$ & 1 & 1 & 1 & 1 \\
\hline \multicolumn{7}{|l|}{ 1cation } \\
\hline ertiary & $4(10.3)$ & $35(89.7)$ & $0.072(0.022 ; 0.23)$ & 0.000 & $0.169(0.032-0.882)$ & 0.035 \\
\hline econdary & $52(27.2)$ & $139(72.8)$ & $0.235(0.126 ; 0.438)$ & 0.000 & $0.269(0.114-0.636)$ & 0.003 \\
\hline rimary & $48(45.3)$ & $58(54.7)$ & $0.520(0.270 ; 1.003)$ & 0.051 & $0.828(0.340-2.019)$ & 0.678 \\
\hline əducated & $35(61.4)$ & $22(38.6)$ & 1 & 1 & 1 & 1 \\
\hline \multicolumn{7}{|l|}{ rital status } \\
\hline Iarried & $90(29.8)$ & $212(70.2)$ & $0.337(0.185 ; 0.614)$ & 0.000 & & \\
\hline nmarried & $20(51.3)$ & $19(48.7)$ & $0.835(0.363 ; 1.920)$ & 0.671 & & \\
\hline sarated & $29(55.8)$ & $23(44.2)$ & 1 & 1 & & \\
\hline is & $110(32.2)$ & $232(67.8)$ & 1 & & & \\
\hline \multicolumn{7}{|l|}{$\mathrm{k}$ of vaccine } \\
\hline s & $30(68.2)$ & $14(31.8)$ & $4.718(2.406 ; 9.253)$ & 0.000 & & \\
\hline J & $109(31.2)$ & $240(68.8)$ & 1 & & & \\
\hline \multicolumn{7}{|l|}{ kness of child } \\
\hline s & $30(71.4)$ & $12(28.6)$ & $5.550(2.738 ; 11.25)$ & 0.000 & $11.36(4.68-27.55)$ & 0.000 \\
\hline J & $109(31.1)$ & $242(68.9)$ & 1 & & & \\
\hline \multicolumn{7}{|c|}{ k of appointment } \\
\hline s & $12(60)$ & $8(40)$ & $2.906(1.158 ; 7.290)$ & 0.023 & & \\
\hline כ & $127(34)$ & $246(66)$ & 1 & & & \\
\hline \multicolumn{7}{|l|}{ get } \\
\hline s & 17(60.7) & 11(39.3) & $3.078(1.398 ; 6.776)$ & 0.005 & & \\
\hline o & $122(33.4)$ & $243(66.6)$ & 1 & & & \\
\hline
\end{tabular}

\section{Figures}




\section{Timely versus Delayed immunization \\ n delay n timely}

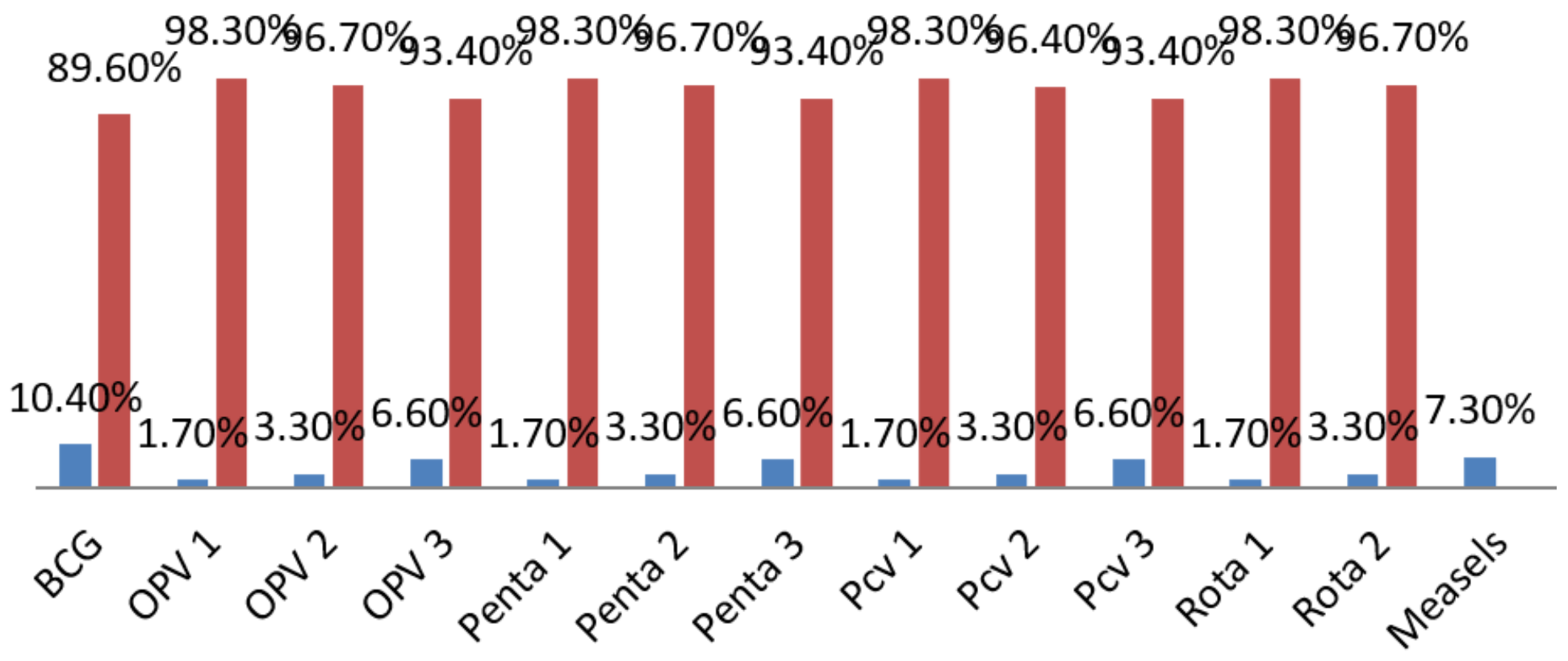

Figure 1

Timely versus delayed immunization among 11-23 months old children in Edagahamus, Tigray, Ethiopia, 2018. 